Ethiopian Journal of Environmental Studies \& Management 8(2): 130 - 140, 2015.

ISSN:1998-0507

doi: http://dx.doi.org/10.4314/ejesm.v8i2.3

Submitted: November 10, 2014

Accepted: February 2, 2015

\title{
PRAGMATIC APPROACH TO THE COMBINATION AND SELECTION OF TANKS FOR WATER DISTRIBUTION PIPE NETWORK BASED ON PRESSURE SIMULATION
}

\author{
*AYANSHOLA, A.M., ${ }^{1}$ MANDAL, K., ${ }^{2}$ BILEWU, S.0. ${ }^{1}$ AND SALAMI, A.W. ${ }^{1}$ \\ ${ }^{1}$ Department of Water Resources \& Environmental Engineering, University of Ilorin, Nigeria \\ ${ }^{2}$ National Institute of Science, Technology and Development Studies, New Delhi, India
}

\begin{abstract}
This paper presents a suitable model for appropriate selection and location of tanks based on pressure requirement at demand nodes for municipal water distribution pipe network. The water distribution pipe network data for the supply zone used as case study was obtained for the analysis. Existing tank locations were documented with the help of Geographical Information System (GIS) tools and possible scenarios were determined based on the tank combination using mathematical combination approach. Hydraulic conditions were simulated with EPANET 2.0 software in order to determine output pressure at demand nodes for various scenarios under consideration. The results obtained from the study area showed that the residual pressure is inversely proportion to the reliability index (i.e. as the pressure value increased, the system become less reliable in term of the number of nodes that can enjoy such higher values of the pressure). This will serve as a guide for the proper operation and management of the network distribution system of the city under consideration. The approach is also suggested for evaluating the most efficient strategies for managing nodal pressures in the strengthening of a distribution system or the planning and development of a new one.
\end{abstract}

Key Words: Hydraulic, Water demand, Node, EPANET, Supply zone, Scenarios

\section{Introduction}

Water distribution systems, comprising of the water tank, pumps, transmission and distribution supply main, valves and fire hydrants, transport water from a treatment facility to the consumer. Consumers are connected to the sources, through hydraulic components such as pipes, valves, and reservoirs. The objectives of the distribution system is to supply water to every house, industrial plants and public places by means of network of pipes at sufficient quantity and desired pressure, without impairing its quality (Ayanshola et $a l ., 2013)$. A water distribution system

*Corresponding Author: Ayanshola, A.M. 130 should be able to provide, during its entire life, the required quality of water for the expected loading conditions with the desired residual pressures at all nodes. Despite the installation of distribution reservoirs within different supply zones, many consumers are still left with either no supply or a supply at very low or sometimes negative pressure. Generally, water distribution systems are designed to provide water to consumers at some agreed level of service which is often defined as a minimum level of pressure at the critical point which is the point of lowest pressure in the system (Mckenzie and Wegelin,

Email: engramayanshola@gmail.com 
2009). In addition, there may be certain fire-flow requirements which can over-ride the normal consumer requirements (Bhave and Gupta, 2006). According to Jacobs and Strijdom (2009), the stipulation of a minimum pressure requirement during water distribution system (WDS) design is to satisfy the customer. A 'too low' pressure head would not be acceptable and could result in numerous customer complaints. In addition it could lead to operation and maintenance problems, with cost implications if equipment is damaged (e.g. pipe collapse due to negative pressure).

Challenges of providing sufficient water at adequate pressure to support growing demands are becoming more enormous in most cities of developing countries. This results from the failure of the distribution system in many urban cities of developing nations. The strengthening of the existing system or the construction of new ones thus become inevitable. This new developments may sometimes not undergo the necessary analysis and design procedure. One of the most important criteria to be considered when there is a need for a new development is the pressure management. A lot of money has been expended by service providers on this without yielding the desired results. About 80 to 85 percent of the cost of water supply goes into the distribution system (Swamee and Sharma, 2008).

Elevated storage tanks are normally provided within distribution systems to supply peak demand rates and equalize system pressures. In general, elevated storage is more effective and economical because of its ability to reduce pumping requirements. It can also serve as a source of emergency supply since system pressure requirements can still be met temporarily when pumps are out of service. A storage tank can be considered to have failed if it runs dry, or failed to produce desired pressure at demand nodes. It is also possible to describe the reliability or lack thereof of a tank through its failure behaviour as opined by Zyl et al. (2008). Increasing the number of tanks and their capacity can reduce pumping costs and invariably improve system reliability if they are effectively positioned and well incorporated into the network.

Water tanks were built at various locations within the metropolis of this study area, Ilorin, central Nigeria, in order to boost the pressure at different locations within the city (Table 1). The idea behind the building of these water tanks was to store the excess water during the low demand periods and release at peak periods. The network will be supplied by water treatment plants together with the water tank. This method aimed at meeting the demand of water network pressure at various nodes. However, most of the tanks were built without thorough evaluation of the number needed for an effective distribution system.

Various techniques exist for the evaluation of a water distribution system. This may include the use of GIS, which is increasingly being co-opted to assign water demand to network nodes based on user classifications such as residential, commercial, industrial, institutional, etc (Filion et al., 2007). Water professionals and researchers had recently found the EPANET software useful in the design, operations and improvement to various water network distribution systems because of its simulation capabilities (Amato, 2014; Adeniran and Oyelowo, 2013). These tools and approach was employed in this work in order to effectively carry out this assignment.

This study therefore seeks to evaluate the existing system based on pressure simulation in order to establish the best 
combination of tanks that will be most effective in the network distribution system. This will serve as a guide for a proper operation and management of the network distribution system of the city under consideration. The approach will be useful for evaluating the most efficient strategies for managing the network in order to reduce high inequality nodal pressure in a supply zone before embarking on strengthening of network distribution system by introducing tanks.

\section{Method and Materials Study Area}

A zone of supply was selected within the Ilorin township water distribution network. Ilorin, the capital city of Kwara State, Nigeria is located between latitudes $8^{\circ} 25^{\prime} \mathrm{N}$ and $8^{\circ} 32^{\prime} \mathrm{N}$ longitudes $4^{\circ} 30^{\prime} \mathrm{E}$ and $4^{\circ} 41^{\prime} \mathrm{E}$ (Figure 1). It presently occupies an area of about $89 \mathrm{Km}^{2}$ (Adeleke, 2010). According to Ayanshola et al. (2013), the population of the city was estimated to be 777,667 in 2007. The zone selected for this study is within the metropolis and is shown in a modified downloaded google earth map described by Figure 2 .

\section{Data Collection}

A digital map of the pipe layout for the town was obtained from the Kwara State Water Board (KSWB), who is the service provider. Information regarding features such as link diameter, length, nodal elevation, tank location and height and all other fittings and appurtenances that constitutes the distribution system was collected. Population data was obtained from the National Population Commission.

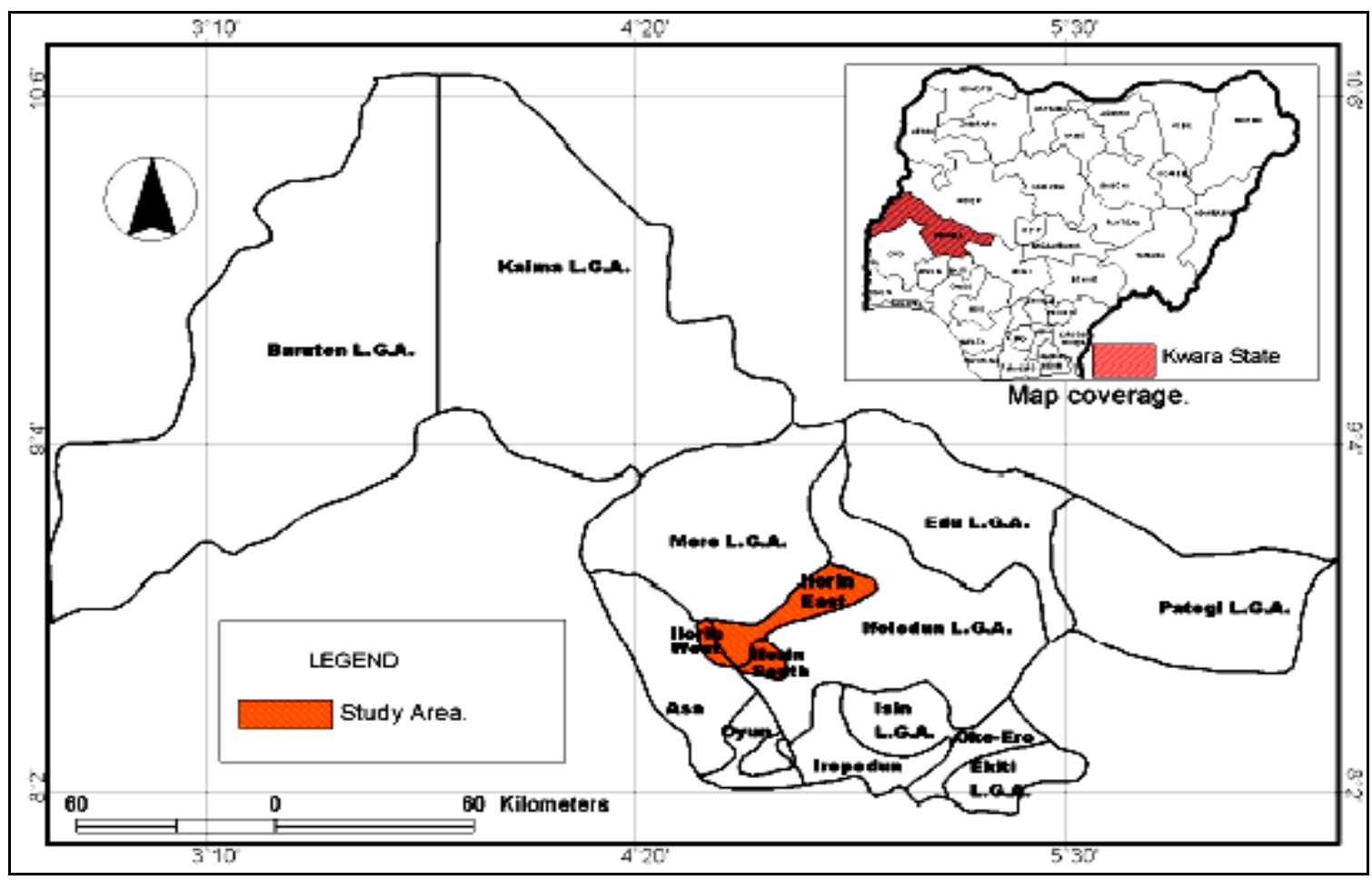

Figure 1: Map of Kwara State Showing the study Area [Source: Adebimpe, 2011]

The supply system in Ilorin is sourced from the Agba, Asa and Moro Rivers. Reservoirs built on these rivers have a total reservoir storage capacity of about $49,100,000 \mathrm{~m}^{3}$ with total treatment plant full capacity operation of about 82,276 
$\mathrm{m}^{3} /$ day. Water pumped from Asa, Agba and Sobi clear water tanks are normally stored in distribution/service reservoirs from where they are delivered by gravity to the various demand areas. Before 1999, seven service reservoirs were connected to the network. Another six overhead steel tanks were introduced in 2001 to enhance the distribution system out of which two are replacements. The location, capacities and the status of the 13 service reservoirs in Ilorin Township are as shown in Table 1 (Ayanshola and Sule, 2006).

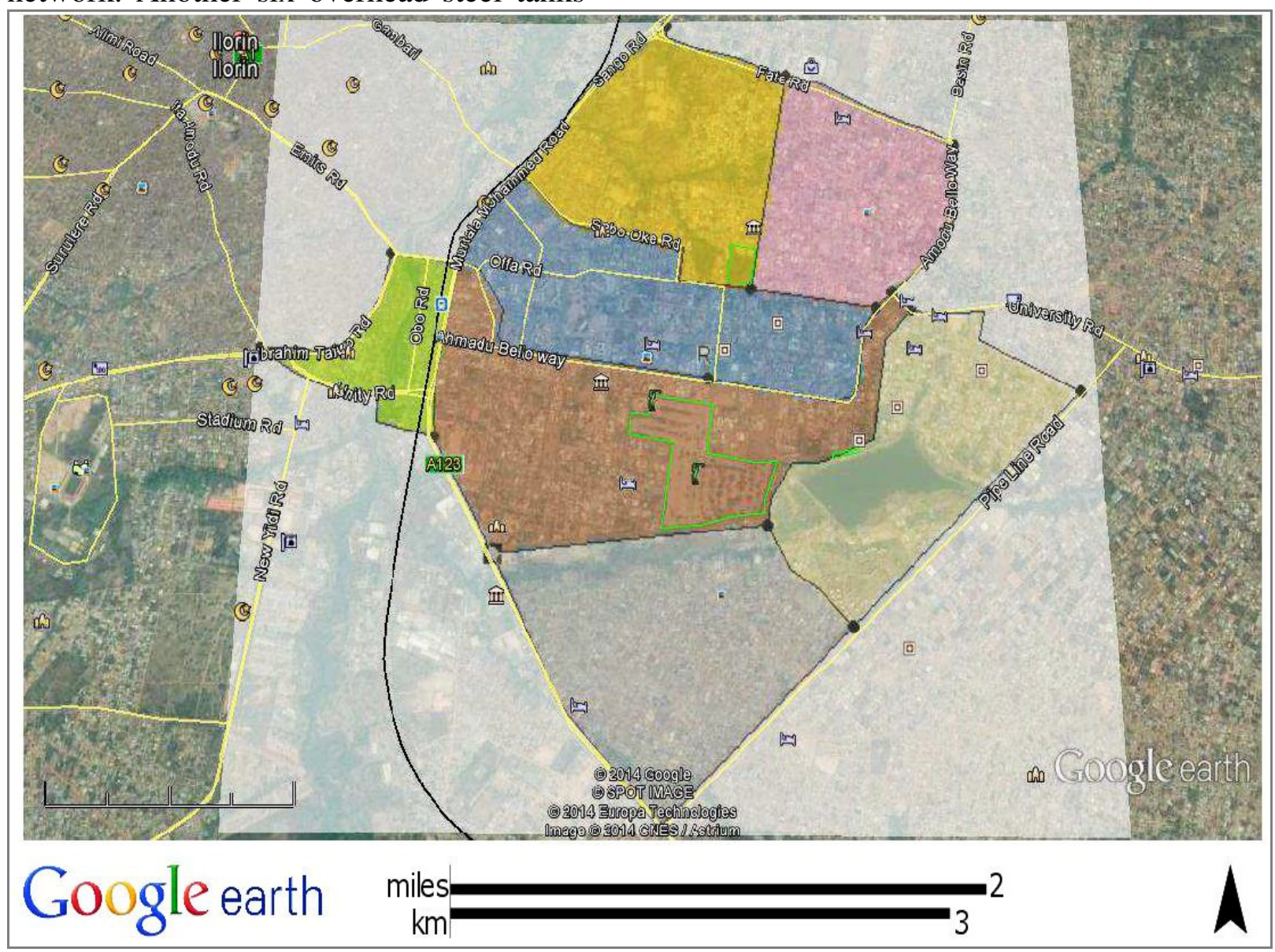

Figure 2: Modified Google Earth Map Showing the study Area

The distribution system in the metropolis is primarily dictated by street patterns, topography, water demand and location of treatment and service reservoirs. For Ilorin Metropolis, the pipe network is made up of Asbestos Cement (AC), Cast Iron (CI), Galvanized Iron (GI) and Unplasticized Polyvinyl Chloride (UPVC) pipes ranging from $50 \mathrm{~mm}$ to $600 \mathrm{~mm}$ diameter and cover a total distance of about $337.542 \mathrm{~km}$. In recent time, there were additional pipelines ranging from $100 \mathrm{~mm}$ to $800 \mathrm{~mm}$ diameter made of D.I. and UPVC which cover a total distance of about $107.869 \mathrm{~km}$ to upgrading the system. Out of the total length of the pipelines, $79.017 \mathrm{~km}$ are new pipelines either for rising main or distribution network while the remaining length of about $28.852 \mathrm{~km}$ were used to replace some of the existing $\mathrm{AC}$ pipelines within the township. 
Table 1: Location, Capacities and Status of Distribution Tanks in Ilorin Township

\begin{tabular}{|c|c|c|c|c|c|c|}
\hline S/no & Tank type & Location & Source & $\begin{array}{c}\text { Capacity } \\
\left(\mathrm{m}^{3}\right)\end{array}$ & $\begin{array}{l}\text { Status as at } \\
2006\end{array}$ & $\begin{array}{l}\text { Present } \\
\text { status }\end{array}$ \\
\hline 1. & Underground Concrete & GRA/Fate & Agba & 4,600 & In use & In use \\
\hline 2. & Overhead Steel & GRA/Fate & Agba & 454.45 & In use & In use \\
\hline 3. & $\begin{array}{l}\text { Eastern Ground Level } \\
\text { Concrete }\end{array}$ & Tanke & Asa & 10,000 & In use & In use \\
\hline 4. & $\begin{array}{l}\text { Western Ground Level } \\
\text { Concrete }\end{array}$ & Adewole Estate & Asa & 10,000 & In use & In use \\
\hline 5. & Overhead Concrete & Former UITH & Asa & 4,600 & In use & In use \\
\hline 6. & Overhead Steel & $\begin{array}{l}\text { Olanrewaju Estate, Offa } \\
\text { Garage }\end{array}$ & Agba & 227.27 & Replaced & Not in use \\
\hline 7. & Overhead Steel & $\begin{array}{l}\text { Olanrewaju Estate, Offa } \\
\text { Garage }\end{array}$ & Agba & 454.45 & In use & In use \\
\hline 8. & Overhead Steel & Oke Sobi, Sobi Road & Sobi & 227.27 & Replaced & Not in use \\
\hline 9. & Overhead Steel & Oke Sobi, Sobi Road & Sobi & 454.45 & In use & In use \\
\hline 10. & Overhead Steel & Central Mosque & Asa & 227.27 & Not in use & removed \\
\hline 11. & Overhead Steel & Central Mosque & Asa & 454.45 & In use & Removed \\
\hline 12. & Overhead Steel & Unity-Taiwo Junction & Agba & 454.45 & In use & In use \\
\hline 13. & Overhead Steel & Kwara Hotel & Agba & 454.45 & In use & In use \\
\hline
\end{tabular}

Data Analysis

\section{Population and Water Demand Calculation}

The projected population of Ilorin for the year 2020 is 1,185,033 from equation 1 . This is based on the 1996 figures provided by the National Population Commission and a geometric growth rate of 2.83 :

$$
P n=P o(1+r)^{n}
$$$$
1
$$

Where $P n=$ Present population, $P o=$ Initial population, $r=$ growth rate and $n=$ number of year.

The NPC did not provide a breakdown of the population of each area within the metropolis and thus the population covered by each loop was based on the assumption that the town has an equal population density for all areas. This means that the population of an area is dependent on the area enclosed by the loop. For an estimated area of $89 \mathrm{~km}^{2}$, the population density is 13 people per square metre. Table 2 shows the areas and corresponding population of the loops under consideration while Table 3 shows the corresponding pipe lengths. All the pipes are $300 \mathrm{~mm}$ in diameter since they are distribution lines. A roughness coefficient of 140 was used for the analysis since the pipes are made of Asbestos Cement (Steel and McGhee, 1984). Total pipe length for each loop was also determined in order to estimate demand in each of the loop shown in Figure 3. All the parameters were determined using the available data from KSWB with the aid of GIS and google earth map. 
Table 2: Water demand along the pipes

\begin{tabular}{|c|c|c|c|c|c|c|c|}
\hline Loop & Pipe composition & Population & Area $\left(\mathrm{m}^{2}\right)$ & $\begin{array}{l}\text { Total } \\
\text { pipe } \\
\text { length } \\
(\mathrm{m})\end{array}$ & $\begin{array}{l}\text { Average } \\
\text { demand } \\
(1 / s)\end{array}$ & $\begin{array}{l}\text { Peak } \\
\text { demand } \\
(1 / s)\end{array}$ & $\begin{array}{l}\text { Consumption } \\
\text { per length } \\
\left.\text { (x } 10^{-3} \mathrm{l} / \mathrm{s} / \mathrm{m}\right)\end{array}$ \\
\hline 1 & JK, KP, PQ, JQ & 18060 & 1389.22 & 6101.26 & 25.08 & 50.17 & 8.22 \\
\hline 2 & $\mathrm{KP}, \mathrm{KL}, \mathrm{LM}, \mathrm{MO}, \mathrm{OP}$ & 13860 & 1066.14 & 3487.25 & 19.25 & 38.50 & 11.04 \\
\hline 3 & IJ, IR, LR, KL, JK & 17561 & 1350.84 & 7095.48 & 24.39 & 48.78 & 6.87 \\
\hline 4 & $\begin{array}{l}\text { FI, DF, DE, EN, MN, } \\
\text { LM, LR, IR }\end{array}$ & 25385 & 1952.68 & 9462.00 & 35.26 & 70.51 & 7.45 \\
\hline 5 & $\mathrm{BE}, \mathrm{EN}, \mathrm{AN}, \mathrm{AB}$ & 16191 & 1245.50 & 6038.85 & 22.49 & 44.98 & 7.45 \\
\hline 6 & $\mathrm{BE}, \mathrm{BC}, \mathrm{CD}, \mathrm{DE}$ & 19834 & 1525.69 & 5950.78 & 27.55 & 55.09 & 9.26 \\
\hline 7 & FG, GH, HI, FI & 6030 & 463.82 & 4244.86 & 8.37 & 16.75 & 3.95 \\
\hline
\end{tabular}

Table 3: Pipe Lengths

\begin{tabular}{ll|ll}
\hline Pipe ID & Length $(\mathrm{m})$ & Pipe ID & Length $(\mathrm{m})$ \\
\hline AB & 2027.93 & GH & 1231.66 \\
BC & 1602.54 & HI & 448.92 \\
CD & 1808.23 & IJ & 716.69 \\
DE & 1757.20 & JK & 1945.61 \\
BE & 782.82 & KP & 1379.97 \\
EN & 1816.15 & OP & 1204.68 \\
AN & 1411.96 & MO & 1127.35 \\
MN & 134.52 & KL & 849.22 \\
LM & 131.716 & JQ & 1397.96 \\
FI & 1099.11 & PQ & 1378.73 \\
DF & 939.34 & LR & 1880.52 \\
FG & 1465.16 & IR & 1703.45 \\
\hline
\end{tabular}

\section{Tank Combinations and Scenarios}

The general methodology of this hydraulic simulation and analysis was to examine the pressure variations of different service reservoirs combinations within the zone under consideration. The possible number of combination for the service reservoirs in a service zone is given by:

Table 4: Possible tank combinations

\begin{tabular}{l|ll}
\hline No of tanks $(n)$ & No Combined $(R)$ & Possible No of Combinations $(C)$ \\
\hline 5 & 1 & 5 \\
5 & 2 & 10 \\
5 & 3 & 10 \\
5 & 4 & 5 \\
5 & 5 & 1 \\
\hline TOTAL & & 31 \\
\hline
\end{tabular}

$$
n C r=\frac{n !}{(n-r) ! r !} \quad 2
$$

Where: $C$ is the possible number of combination without repetition, $n$ is the total numbers reservoirs in the supply zone and $r$ is the number of reservoirs to be combined at a time. Based on equation 2 , the total number of possible scenarios (combinations) is 31 and the breakdown is in Table 4. 


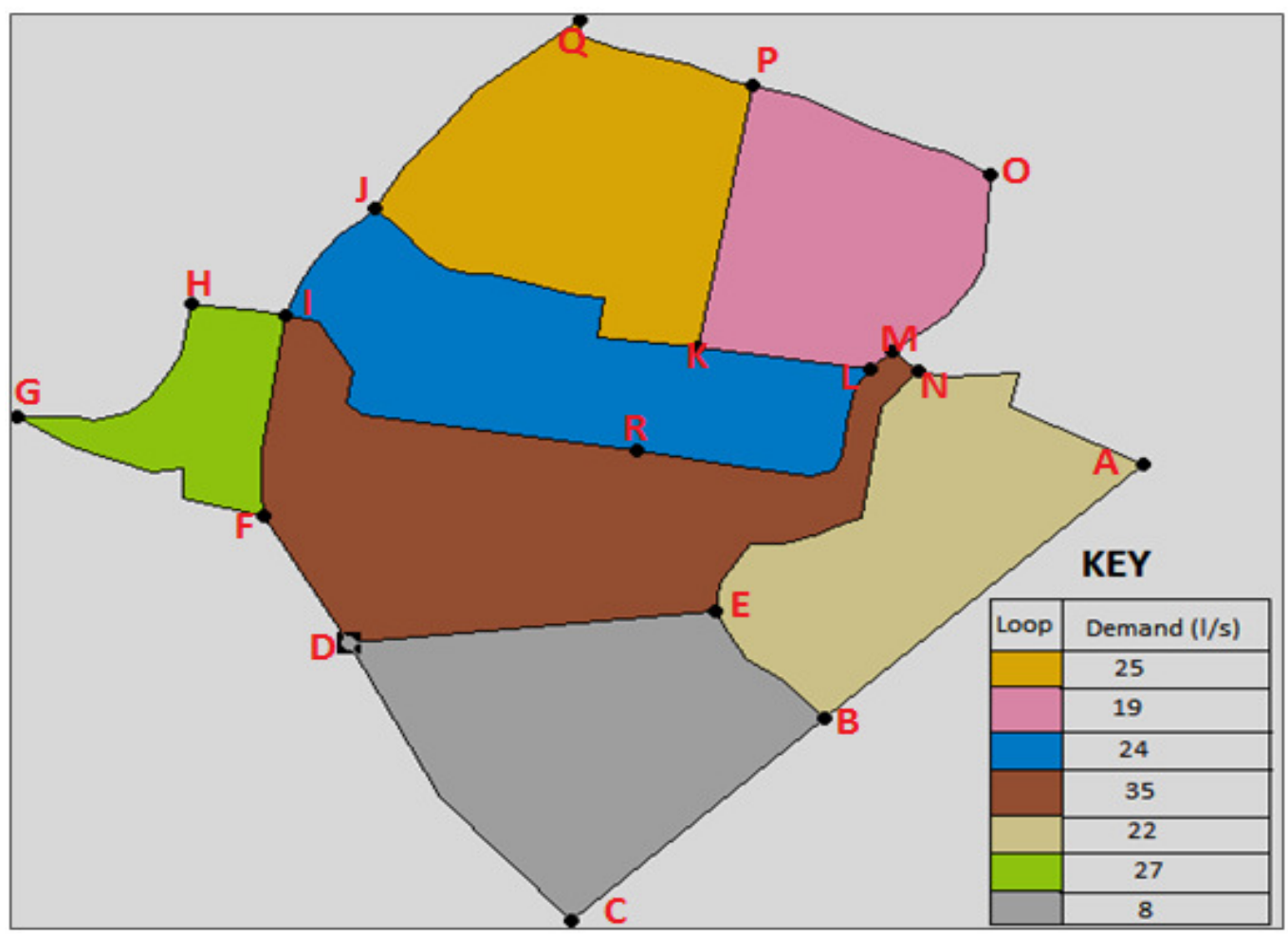

Figure 3: Pipe Network Distribution Zone Showing Demand Variation

\section{Pressure Simulation and Analysis}

Pressure was the primary hydraulic parameter analysed using EPANET 2.0 software to identify the best combination of the service reservoirs to serve a distribution zone effectively. The target minimum and maximum residual pressure are $5 \mathrm{~m}(7 \mathrm{psi})$ and $70 \mathrm{~m}(99 \mathrm{psi})$ respectively during peak hour demand conditions. This range of residual pressure has been found to be adequate for municipal water supply system (Ayanshola and Sule, 2006). EPANET uses the same numerical engines as WaterCAD and other commercially available software. Several commercial simulation models are available, but in this study EPANET 2.0 was used to perform hydraulic simulation. EPANET 2.0 fulfils the requirement of calculating nodal pressures and its source code is available free of cost in the public domain. It can also be applied to large water distribution networks with unlimited pipe numbers (Adeniran and Oyelowo, 2013; Avesani et al., 2014).

EPANET's hydraulic simulation model computes hydraulic heads at junctions and flow rates through links for a fixed set of reservoir levels, tank levels, and water demands over a succession of points in time (Ayanshola, 2013; Ayanshola et al., 2013). The principle of EPANET network analysis is based on the following two conditions (Adeniran and Oyelowo, 2013; Avesani, et al., 2014): the algebraic sum of the pressure drops around a closed loop must be zero, i.e. there can be no discontinuity in pressure and; the flow entering a junction must be equal to the flow leaving the same junction; i.e. the law of continuity must be satisfied. Based upon these two basic principles, the pipe networks are generally solved by the method of successive approximation (Sil et al., 2012). 


\section{Results and Discussion}

The analysis was performed for 31 scenarios earlier mentioned. The results showed that few scenarios generated the desired level of service in the supply zone. Figure 4 shows the percentage numbers of nodes with positive residual pressure for various scenarios under consideration. The study showed that about $38 \%$ of the total number of scenarios has up to $50 \%$ nodes with positive residual pressure value. Only three cases were found to have $100 \%$ positive pressure while the remaining 28 cases generated negative pressures in more than one node. Such cases with negative pressures at node of demands should be avoided because faecal organisms and culturable human viruses may be present in groundwater adjacent to a pipeline and drawn into network (Chambers et al., 2004).

Further analysis was carried by selecting the best 5 combinations (' 1 and 4', ' 1 and 5', '1, 2 and 4', '1, 4 and 5' and ' $1,2,4$ and 5 ') in order to establish the index of their reliability as shown in Figure 5. These are the cases that had up to $80 \%$ positive pressure at their nodes. The relationship that exists shows that the residual pressure is inversely proportion to the reliability index as shown in Figure 5. As the pressure value increased, the number of nodes that can enjoy high values of pressure reduces. However, the combination of Reservoirs ' 1,4 and 5' yielded the best result as it produces the highest reliability index up to minimum of $5 \mathrm{~m}$ residual pressure. This was followed by the combination of ' $1,2,4$ and 5 ' while the combination of ' 1 and 5 ' is the least desirable of the possible combinations.

The best three scenarios were furthered evaluated as shown in Figures 6. The scenario that made use of the combination of Tanks 1,4 and 5 yielded best result because it spread between the pressure of 5 $\mathrm{m}$ and $30 \mathrm{~m}$. This is a good pressure distribution within the zone under consideration. In this scenario, few nodes will still enjoy as much as $50 \mathrm{~m}$ residual pressure. A scenario with Tanks 1 and 4 shows that no nodes have a pressure range between $15 \mathrm{~m}$ and $30 \mathrm{~m}$ even though few nodes enjoy higher residual pressure that tops $49 \mathrm{~m}$. For the ' $1,2,4$ and 5' combination, there is no even distribution of pressure among the nodes. Most nodes experience higher and lower residual pressure.

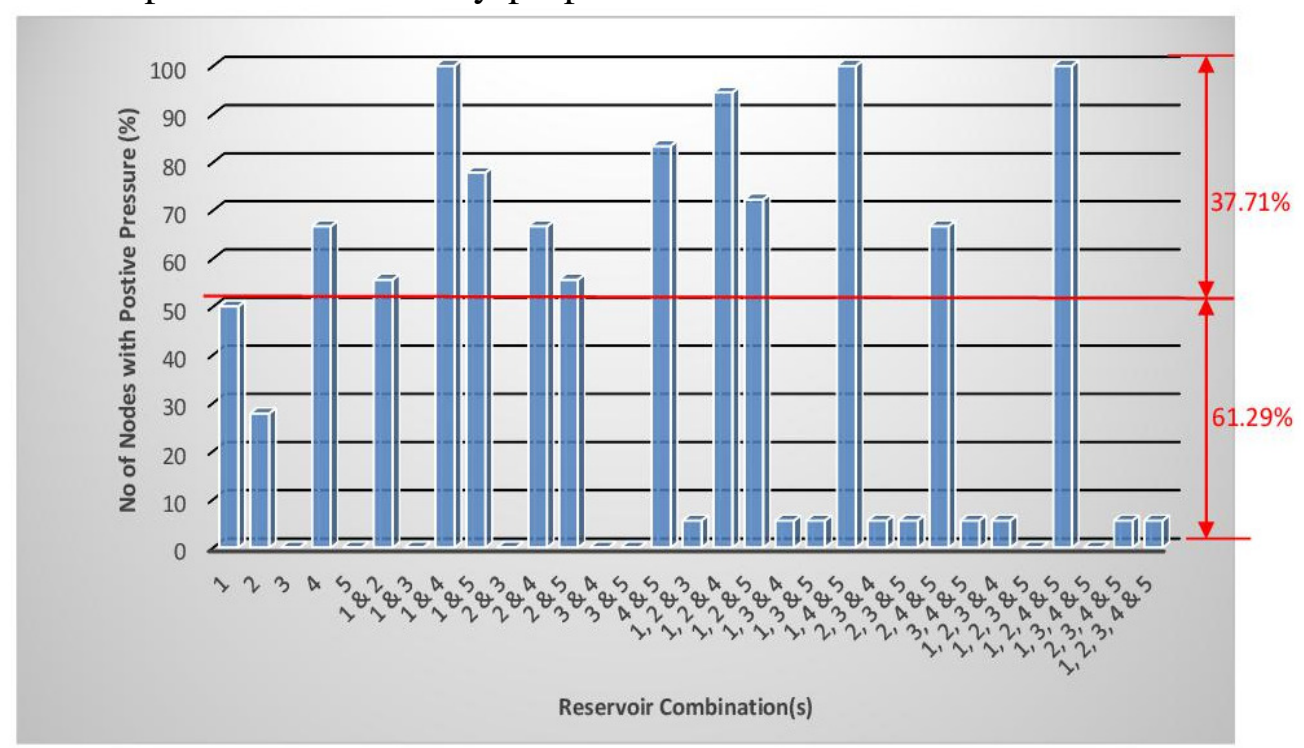

Figure 4: Variation of Percentage Number of Nodes for Various Tank Combinations 


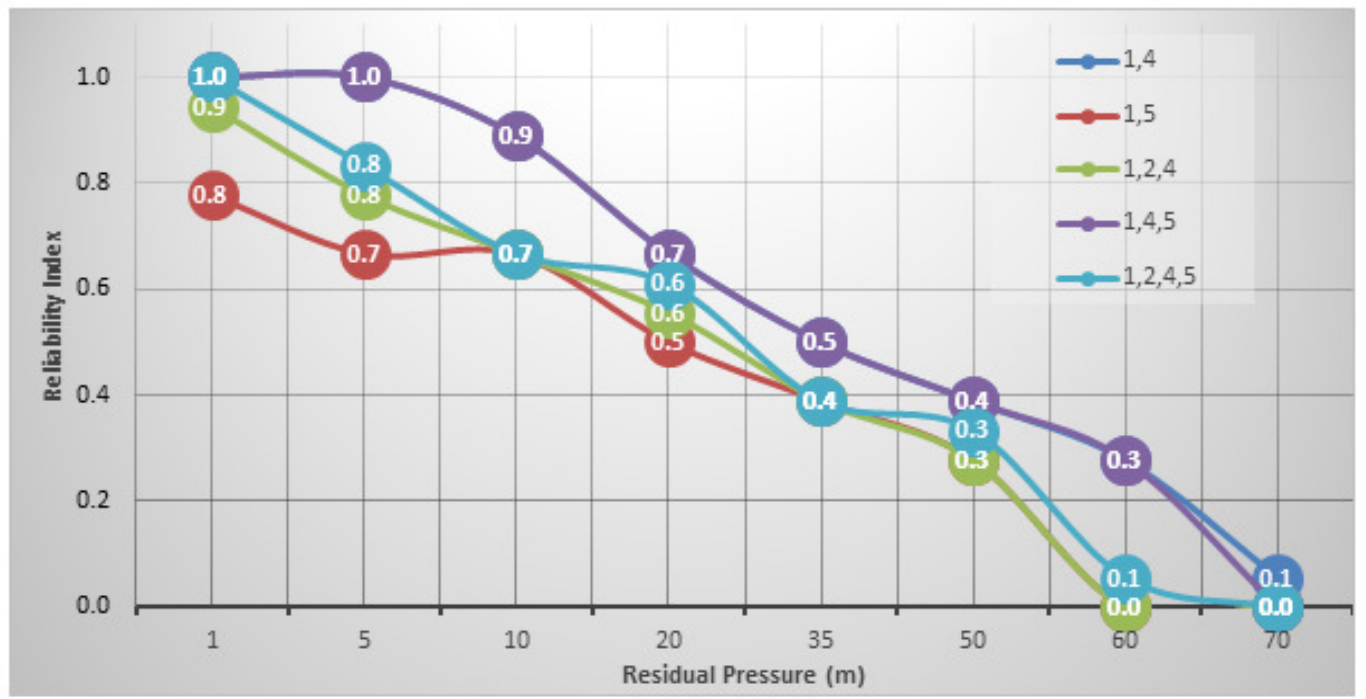

Figure 5: Reliability Index and Pressure Variation

Figure 7 shows the spatial variation of pressure simulated for the scenario with Tanks 1, 4 and 5 combined. The loops around nodes A, B, C and D has the highest pressure and it kept on reducing towards nodes $\mathrm{O}, \mathrm{P}$ and $\mathrm{Q}$. However, they all fall within the minimum desirable pressure for a municipal water supply system.

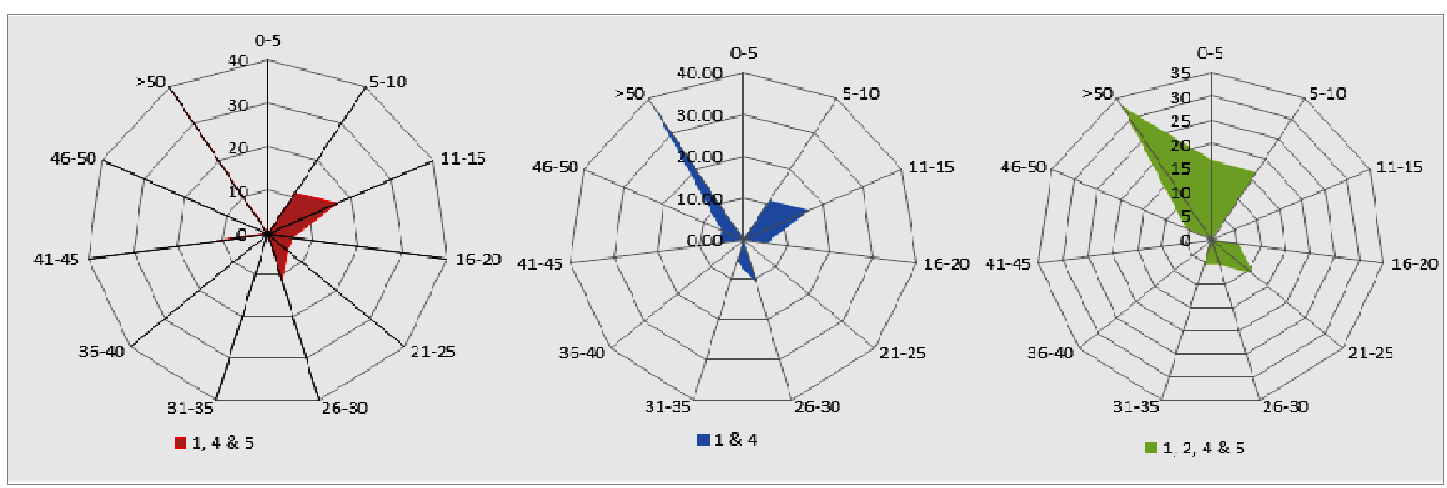

Figure 6: Pressure Variation with Percentage Number of Nodes for the Best Three Identified Combinations of Tanks 


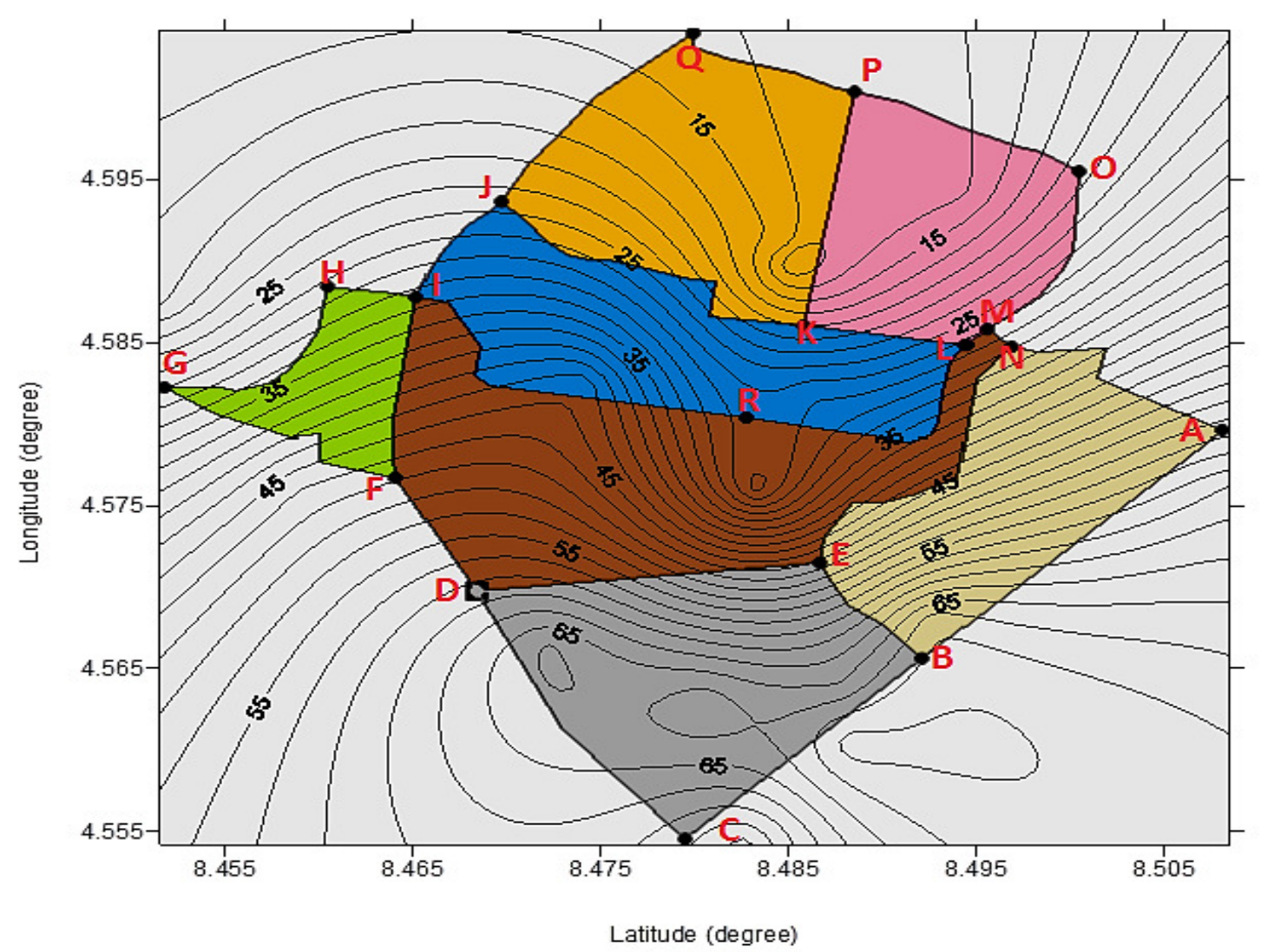

Figure 7: Spatial Variation of Simulated Pressure for Various Demand Zone

\section{Conclusion}

This study evaluated an existing system of location of storage reservoirs based on pressure simulation in order to establish the best combination of reservoirs that will be most effective in the network distribution system. The results obtained from the study area showed that the residual pressure is inversely proportion to the reliability index. This finding will serve as a guide to the proper operation and management of the network distribution system of the city under consideration. This approach will also find relevance when embarking on the strengthening of a network distribution system by the introduction of overhead reservoirs or in new developments.

\section{Acknowledgement}

The authors acknowledge the Council of Scientific and Industrial Research (CSIR), India and The World Academy of Science
(TWAS), Italy for the award of CSIRTWAS Postdoctoral Fellowship programme to the lead author. The fellowship was undertaken at the CSIR-National Institute of Science, Technology and Development Studies (NISTADS), New Delhi, India where this article was prepared.

\section{References}

Adebimpe, R.U. (2011), Climate changes related disasters and vulnerability: an appraisal of the Nigerian policy environment, Environmental Research Journal, 5(3): 97-103.

Adeleke, O.O. (2010), Empirical modelling of delays at traffic warden controlled urban intersections: case study of Ilorin, Nigeria, PhD Thesis, Department of Civil Engineering, University of Ilorin, Ilorin, Nigeria.

Adeniran, A.E. and Oyelowo, M. A. (2013), An EPANET analysis of 
water distribution network of the University of Lagos, Nigeria, Journal of Engineering Research (JER), Faculty of Engineering, University of Lagos, Nigeria. 18(2): 69-83.

Amato, V. (2014), Mathematical models for the management of water distribution networks, Edizioni Accademiche Italiane, Saarbrucken, Deutschland/Germany.

Avesani, D., Righetti, M., Rigiietti, D. and Bertola, P. (2012), The extension of EPANET source code to simulate unsteady flow in water distribution networks with variable head tanks, Journal of Hydroinformatics, WWA Publishing, 14(4): 960-973.

Ayanshola, A.M. (2013), Evaluation of supply reliability and sustainability of household water use in Ilorin, Kwara State, Nigeria, Ph.D. Thesis, Department of Civil Engineering, University of Ilorin, Ilorin, Nigeria.

Ayanshola, A.M. and Sule, B.F. (2006): Assessment of flow pressure in selected zones of Ilorin township water supply. Journal of Research Information in Civil Engineering (RICE), Department of Civil Engineering University of Ilorin; 3(1), 83-101.

Ayanshola, A.M., Sule, B.F. and Salami, A.W. (2013); An optimization model for sustainable water distribution network design, Journal of Engineering Research (JER), Faculty of Engineering, University of Lagos, Nigeria. 18(2): 55-67.

Bhave, P.R. and Gupta, R. (2006), Analysis of water distribution networks, Alpha Science International Ltd, Oxford, UK.
Chambers, K., Creasey, J. and Forbes, L. (2004), Design and operation of distribution networks, Safe Pipe Water: Managing Microbial Water Quality in Pipe Distribution Systems, World Health Organization Publication, edited by Ainsworth, R., IWA Publishing, London, UK, pp 38-68.

Filion, Y., Adams, B. and Karney, B. (2007), Cross correlation of demands in water distribution network design, Journal of Water Resources Planning and Management, 133(2): 137-144.

Jacobs, H.E. and Strijdom, J.L. (2009), Evaluation of minimum residual pressure as design criterion for South African water distribution systems, Water SA, 35(2): 183-191 http://www.wrc.org.za

Mckenzie, R.S. and Wegelin, W. (2009), Implementation of pressure management in municipal water supply systems, IWA Press Paper No.0309, 18 pp.

Sil, B.S., Kumar, A., Saikia, P., Bui, P.J. and Banerjee, P. (2012), Computation of least cost pipe network - an alternate method, International Journal of Computational Engineering Research, 3(2): 137-142.

Steel E.W. and McGhee T.J. (1984), Water Supply and Sewerage, $5^{\text {th }}$ Edition, McGraw-Hill International Book Company, Tokyo.

Zyl, J.E.V., Piller, O. and Gat, Y.I. (2008), Sizing municipal storage tanks based on reliability criteria, Journal of Water Resources Planning and Management, ASCE, 134(6): 548555. 